\title{
Fumed silica as a filler for MUPF resin in the process of manufacturing water-resistant plywood
}

\author{
Dorota Dukarska $^{1} \cdot$ Rafał Czarnecki $^{1}$
}

Received: 4 May 2014/Published online: 28 July 2015

(c) The Author(s) 2015. This article is published with open access at Springerlink.com

\begin{abstract}
This work examines the effect of applying fumed silica with nanoscopic-size particles as a filling material for melamine-urea-phenol-formaldehyde (MUPF) resin in the process of manufacturing water-resistant plywood. Moreover, this paper investigates the possibility of reducing the amount of MUPF resin mixture used in the process of gluing veneer sheets. Based on the investigations into the reactivity, viscosity and durability of MUPF resin mixture containing various amounts of nanofiller, it was found that the optimum amount of silica that can make the resin suitable for gluing sheets of veneer amounts to 2 PBW per 100 PBW of MUPF resin. The gluing properties for thus mixed resin were determined by measuring the contact angle and determining the parameters of its derivatives, which are an additional criterion for evaluating the gluing properties. The thermal stability was tested with simultaneous use of TG-DSC analysis. The experimental plywood manufactured using optimal nano- $\mathrm{SiO}_{2}$ was tested in terms of bond quality and mechanical properties according to appropriate standards. The investigations prove that it is possible to apply fumed silica as a filling material for the resin in the process of manufacturing water-resistant plywood. Introducing the above-mentioned amount of fumed silica into the resin makes it possible to increase the activation energy of the cross-linking process of MUPF resin and to optimize the process of gluing the sheets of veneer. Moreover, it is also possible to produce
\end{abstract}

Dorota Dukarska

ddukar@up.poznan.pl

1 Department of Wood Based Materials, Faculty of Wood Technology, Poznan University of Life Sciences, ul. Wojska Polskiego 38/42, 60-627 Poznan, Poland plywood of the required water-resistance with the amount of adhesive mixture reduced by $30 \%$.

\section{Introduction}

The filling materials for resins, which are contemporarily used in plywood industry, enhance the reactivity of the adhesives and regulate their viscosity. Thus, they restrain the excessive penetration of the resin into wood. Moreover, these fillers are made of relatively big particles, which limit their mobility in the cross-linking process and make it difficult to attain high level of homogenization. Consequently, it is difficult to apply the resin mixture onto the surface of veneer and it is necessary to use a larger amount of resin. What is more, amylaceous substances used as fillers of amine resins are totally nonresistant to the action of fungi (Proszyk 1990). In recent years, owing to the growing interest in nanotechnology and use of nanoparticles, it has been possible to produce a number of new materials of increased utilitarian value, better mechanical strength and higher resistance to chemical and thermal conditions. In addition, the costs of their production have been optimized and reduced. At present the most commonly used filler with nanoscopic size of particles is silica, i.e., silicon dioxide. Silica is capable of creating both silicon nanostructures, consisting of only $\mathrm{SiO}_{2}$ particles, and the hybrid ones where it plays the role of a core covered with a thin layer of another material. Nowadays the most widely used method of obtaining silica is the sol-gel process, in which silica is obtained from tetraethoxysilane (TEOS), and fumed silica. The activity of nanosilica results from the presence of siloxane groups $\equiv \mathrm{SiO}-\mathrm{Si} \equiv$ and silanol groups $\equiv \mathrm{SiOH}$ on its surface (Barthel et al. 2002; Jesionowski et al. 2002). 
Numerous investigations on the possible uses of nanosilica show that it plays a crucial role in improving the properties of plastic. It results from, for example, the presence of functional groups on its surface, the possibility of attaining high dispersion level and the nanoscopic size of initiating particles. According to Sadej-Bajerlain et al. (2011), the simplest method of nano- $\mathrm{SiO}_{2}$ dispersion in the process of producing polymer nanocomposites is in situ polymerization: silica is dispersed in a monomer. A lot of plastics are characterized by insufficient resistance to the action of chemical substances as well as low dimensional stability and mechanical strength at increased temperatures. Introducing nanosilica into polymers, such as linear low-density polyethylene (LLDPE) (Huang et al. 2004), polypropylene (Azinfar and Ramazani 2013), epoxy resin (Shirono et al. 2001), phenolic resin (Periadurai et al. 2010) or into construction materials, for instance polyethersuflone (PES), polyetherketone (PEEK) and polyimide, polyetherimide improves their properties (Sadhan and Sachin 2001). It is manifested by the increase in modulus of elasticity, modulus of rupture, internal bond, impact strength as well as thermal and chemical resistance. It is also commonly known that fumed silica enhances thermal, rheological and mechanical properties of various types of adhesives, such as thermoplastic polyurethane (Vega-Baudrit et al. 2006), poly(vinyl acetate) (PVAc) (Bonnefond et al. 2013), urea-formaldehyde (Leonovich et al. 2002; Lin et al. 2006; Roumeli et al. 2012; Dukarska 2013) and starch-based wood adhesives (Wang et al. 2011).

Nanotechnology is an interdisciplinary branch of science and it creates new opportunities also in the field of wood science and technology. The greatest achievements so far have been attained for the coating of wood and wood based materials surface. Owing to nanotechnology, researchers developed a number of new, specialist, socalled smart coatings which are produced by using nano$\mathrm{SiO}_{2}$. In case of liquid systems, the universal use of $\mathrm{SiO}_{2}$ as a filler results from its strong condensing properties, which enhance the utilitarian value of paints, lacquers and adhesives (Leder et al. 2002; Carneiro et al. 2012; Moon et al. 2013). The spatial structure of silica protects the system from draining and improves the spreading and smoothness of coating. In the compositions including particulate matter, such as pigment, silica prevents them from sedimentation. The presence of silica in lacquers and enamels enhances their thermal, optical and mechanical resistance, especially to abrasion and scratching. It also makes it possible to attain the desired gloss level of the coating (Royall and Donald 2002; Sow et al. 2011). The use of nano- $\mathrm{SiO}_{2}$ in the system with urea resin and wood preservative enhances fire resistance of wood as well as its dimensional stability and durability (Shi et al. 2007). The review of literature on the subject shows that so far no extensive studies have been conducted on the use of nanosilica in the process of manufacturing wood based materials. Researchers investigated mainly the possibility of using fumed silica and colloidal silica as an auxiliary agent in the process of producing particleboards glued with urea-formaldehyde resin. These research works determined the influence of silica on the structure of the cured UF resin and showed that the addition of silica into the resin results in the increase of its viscosity; yet, it does not significantly affect its cross-linking time or thermal stability and the produced boards have better physicomechanical properties (Leonovich et al. 2002; Lin et al. 2006; Roumeli et al. 2012). Owing to the anti-sedimentation properties of nano$\mathrm{SiO}_{2}$, it was possible to produce, by using phenolformaldehyde resin, water-resistant plywood of light-color adhesive bonds (Dukarska and Łęcka 2009). In these investigations, white pigment, in the form of titanium dioxide, and a small amount of nanosilica were introduced into the adhesive mixture and, therefore, the resin-pigment system became more stable.

The aim of the present work was to examine the effect of applying synthetic fumed silica with nanoscopic-size particles as a filling agent for MUPF resin in the process of manufacturing water-resistant plywood. Taking into consideration the relatively high price of MUPF resin, as well as the fact that, at present, the technology is focused on reducing the material costs, an attempt was made to produce experimental plywood using the minimum amount of MUPF mixed glue.

\section{Materials and methods}

For research purposes, an industrial melamine-urea-phenol-formaldehyde resin (Melfemo 510, produced by Silekol, Kedzierzyn-Kozle, Poland) was used. The resin is used in the production of water-resistant plywood of the following parameters: dry matter-64\%, density$1.290 \mathrm{~g} / \mathrm{cm}^{3}$, viscosity $-840 \mathrm{mPa} \mathrm{s}$, gel time at $100{ }^{\circ} \mathrm{C}$ $210 \mathrm{~s}, \mathrm{pH}-8.95$ and miscibility with water 0.8 . As a filling agent, hydrophilic fumed silica Orisil 200 (Ukraine Orisil Kalusb, Subsidiary of Orisil, Ltd) was applied with a specific surface area $200 \mathrm{~m}^{2} / \mathrm{g}, \mathrm{SiO}_{2}$ content $\geq 99.8$, bulk density approx. $30 \mathrm{~g} / \mathrm{l}$ and average primary particles size $12 \mathrm{~nm}$.

To determine the optimum amount of silica, so that the resin has the proper utilitarian value, a number of tests were carried out using various amounts of nano- $\mathrm{SiO}_{2}$, i.e. 1.0, 1.5, 2.0 parts by weight (PBW) per $100 \mathrm{PBW}$ of MUPF resin. As the proper degree of homogenization and dispersion of nanofiller particles was needed to be attained, the mixed resin was made by using CAT-500 homogenizer 
at 1000 RPM. The usability of the specific mixed resins for the process of gluing veneer sheets was determined on the basis of the following factors: gel time measurements at $100{ }^{\circ} \mathrm{C}$ according to the Polish standard PN-C-89352-3 (1996), activation energy of the cross-linking process, viscosity and its changes at $22{ }^{\circ} \mathrm{C}$ with use of Brookfield DV-II + Pro viscometer. The activation energy was determined according to Kissinger and Ozawa methods based on differential scanning calorimetry DSC using Setaram company LABSYS TM thermobalance. For these tests, closed aluminum crucibles, four heating rates: 3,5 , 10 and $20{ }^{\circ} \mathrm{C} / \mathrm{min}$ in the temperature range $20-200{ }^{\circ} \mathrm{C}$ and helium flow of $2 \mathrm{dm}^{3} / \mathrm{h}$ were applied.

Theories by Kissinger (1957) and Ozawa (1965) are based on the assumption that, for various heating rates, the maximum heat flow corresponds to the higher reaction rate. The basis for determining the activation energy with these methods is the Arrhenius equation:

$k=A e^{\left(\frac{-E_{a}}{R T}\right)}$

where: $k$ rate constant, $A$ pre-exponential factor, $E_{a}$ activation energy $(\mathrm{kJ} / \mathrm{mol}), R$ gas constant $(\mathrm{kJ} / \mathrm{mol} \mathrm{K}), T$ absolute temperature (K). The DSC analysis interprets the equation as (Kim et al. 2006; Kandelbauer et al. 2009):

$\frac{d \alpha}{d t}=A \exp \left(-\frac{E_{a}}{R T}\right) \cdot(1-\alpha)^{n}$

where $\alpha$ is determined on the basis of enthalpy of crosslinking reaction in the time $t$ and the enthalpy of the crosslinking process termination determined from DSC thermograms.

$\alpha=\frac{\Delta H_{t}}{\Delta H_{\text {total }}}$

Therefore, the dependence (1) can be shown as below equation

$\ln k=\ln \left[\frac{\left(\frac{d \alpha}{d t}\right)}{(1-\alpha)^{n}}\right]=\ln A-\frac{E_{a}}{R T}$

According to Kissinger method:

$E_{a} \Phi\left(R T_{p}^{2}\right)=A e^{\frac{-E_{a}}{R T_{p}}}$

where $\Phi$ is the heating rate defined according to the dependence: $\Phi=d T / d t$. After having taken a logarithm of Eq. (5), the Kissinger equation takes the form of:

$-\ln \left(\Phi T_{p}^{2}\right)=-\ln \left(A \frac{R}{E_{a}}\right)+\left(\frac{1}{T_{p}}\right)\left(\frac{E_{a}}{R}\right)$

Thus, the value $E_{a}$ determined on the basis of DSC analysis at various heating rates was specified by the use of dependencies diagram $-\ln \left(\Phi / T_{p}^{2}\right)$ in the function $1 / T_{p}$, where $T_{p}$ is the peak temperature.
In the method proposed by Ozawa, the characteristic temperatures are determined for the accepted constant conversion rates $(\alpha)$ according to the equation:

$\log \Phi=-0.4567 \frac{E_{a}}{R T}+\left[\log A \frac{E_{a}}{R}-2.315-\log F(\alpha)\right]$

where $F(\alpha)$ :

$F(\alpha)=\ln \frac{1}{1-\alpha}$

Additionally, for the resin with the selected amount of nano- $\mathrm{SiO}_{2}$, thermal stability in polythermal conditions was determined by carrying out the simultaneous TG-DSC thermal analysis. The analysis was made in the temperature range $20-260{ }^{\circ} \mathrm{C}$ by the use of open platinum crucibles, helium flow $2 \mathrm{dm}^{3} / \mathrm{h}$ and heating rate $5{ }^{\circ} \mathrm{C} / \mathrm{min}$.

The adhesive properties of the investigated resin mixture were determined by evaluating the interactions occurring on the wood-adhesive phase boundary: the contact angle was determined by means of the method described by, among others, Liptàkovà and Kúdela (1994, 2002), Kúdela and Liptáková (2006). To prepare the samples for investigations, the prepared adhesive mixture was applied on one side of the birch boards at a spread rate of $160 \mathrm{~g} / \mathrm{m}^{2}$. After 5 min the boards were covered with anti-adhesive film and pressed in a single opening laboratory press at a unit pressure of $0.5 \mathrm{MPa}$. Next, after the anti-adhesive film had been removed, a drop of redistilled water, with volume of $5.1 \mu$, was applied to the surface of the cured resin. The contact angle was measured after $10 \mathrm{~s}$ by recording changes in the shape of the drop. Taking into consideration the porous structure of wood, the contact angle was determined by means of the dynamic sessile drop method according to Eq. 9:

$\operatorname{tg} \frac{\theta}{2}=\frac{2 h}{d}$

where $\theta$ contact angle, $h$ height of the drop, $d$ width of the drop in the place it touches the surface. In these calculations, based on the data from literature, the following values were employed for free surface energy of water (Liptáková and Kúdela 1994): $\quad \gamma_{\mathrm{s}}=72.8 \mathrm{~mJ} / \mathrm{m}^{2}$, $\gamma_{\mathrm{s}}^{\mathrm{d}}=21.8 \mathrm{~mJ} / \mathrm{m}^{2}, \gamma_{\mathrm{s}}^{\mathrm{p}}=51.0 \mathrm{~mJ} / \mathrm{m}^{2}$.

The experimental plywood was produced from three layers of birch veneer with thickness of $1.4 \times 1.7 \times 1.4$ and humidity content of $7 \%$. The adhesive was applied in the amount of $180,160,120$ and $100 \mathrm{~g} / \mathrm{m}^{2}$ of veneer. The pressing process was conducted at $140{ }^{\circ} \mathrm{C}$ with unit pressure of $1.6 \mathrm{~N} / \mathrm{mm}^{2}$ in the time of $4 \mathrm{~min}$. Next, the quality of the bond was evaluated according to EN 314-1 (2004) by shear testing $\left(f_{v}\right)$ after ageing tests. According to standard EN 314-2 (1993), tests required for class 2 bond 
quality were applied, i.e. soaking plywood in water at a temperature of $(20 \pm 3){ }^{\circ} \mathrm{C}$ and boiling the investigated samples for $6 \mathrm{~h}$, next cooling in water at a temperature of $(20 \pm 3)^{\circ} \mathrm{C}$ for at least $1 \mathrm{~h}$. The shear test was conducted on wet samples. The mechanical properties were determined by measuring the modulus of rupture $\left(f_{m}\right)$ and modulus of elasticity $\left(\mathrm{E}_{\mathrm{m}}\right)$ parallel (II) and perpendicular $(\perp)$ to the grain in the face layers, according to EN-310 (1993). To investigate the influence of nano- $\mathrm{SiO}_{2}$ added to MUPF resin upon the class of formaldehyde release in the experimental boards, the level of formaldehyde emission was determined by means of the flask method according to EN 717-3 (1996).

To analyze the results of these investigations, a control sample was made according to an industrial recipe: MUPF resin with addition of a traditional amylaceous filler, i.e. $5.65 \mathrm{PBW}$ of rye flour per $100 \mathrm{PBW}$ of the resin and plywood glued with this mixture in the amount of $180 ; 160$; 120 and $100 \mathrm{~g} / \mathrm{m}^{2}$.

For each investigated variant, two sheets of plywood were produced and ten samples were collected from each sheet. The attained results were subjected to statistical analysis using Statistica software, version 10. The average values and standard deviation of the investigated properties were determined and, based on Tuckey's test, the post hoc analysis was made by specifying the homogeneous groups of the mean values of bond quality, modulus of rupture and modulus of elasticity for each investigated variant with the significance level $\alpha=0.05$.

\section{Results and discussion}

The effect of various amounts of nano- $\mathrm{SiO}_{2}$ added to MUPF resin by measuring the gel times at $100{ }^{\circ} \mathrm{C}$, the activation energy and changes in viscosity in time at $20{ }^{\circ} \mathrm{C}$. The analysis of the obtained values shows that substituting amylaceous filler with particles of nano- $\mathrm{SiO}_{2}$ does not considerably affect the gel time of the investigated adhesives (Table 1). However, it was found that the increase in the amount of $\mathrm{SiO}_{2}$ decreases the value of activation energy of the cross-linking process of the resin (Table 1). These values, determined using Kissinger and Ozawa methods, are lower than those of control samples (variant 0 ) by max. $25 \%$. The phenomenon can be explained by the different dynamics of mass decrement and heat flow in the course of the cross-linking process in the investigated adhesives; these values, provided on the basis of TG and DSC thermal analysis, are discussed in more detail in the further part of the paper.

The data included in Fig. 1 provide evidence that the increase in the amount of silica in the adhesive results in the growth of its viscosity. By introducing 2 PBW of silica per $100 \mathrm{PBW}$ of the resin it was possible to attain viscosity values comparable to those of the control adhesive, which was made according to the industrial recipe. It is noteworthy, that with such a composition of the adhesive, the viscosity determined after $4 \mathrm{~h}$ since its preparation was $30 \%$ lower than that of the control adhesive. Such a significant decrease in the dynamics of changes in time makes it possible to lengthen its durability in the production process when compared to the adhesive containing amylaceous filler. Adhesive mixtures containing less than 2 PBW of silica are characterized by lower viscosity than the reference resin, below the value attainable for industrial conditions. Using those adhesives for gluing sheets of veneers could result in excessive penetration of the resin into the veneer as well as bleed-through on their surface. Moreover, the layer of adhesive remaining on the surface may be insufficient to produce a good quality bond (Sellers 1989). That is why, in the further part of the research work, testing of these variants was given up. Taking into consideration the results of tests on the reference adhesive and resin mixtures containing various amounts of nano- $\mathrm{SiO}_{2}$, the conclusion was drawn that the optimum amount of silica, that makes the adhesive useful, is $2 \mathrm{PBW}$ per 100 PBW of MUPF resin. The resin is then characterized by high homogeneity, proper reactivity and viscosity as well as durability required in the process of manufacturing plywood.

To get a full evaluation of the possible uses of fumed silica in the process of producing plywood glued with MUPF resin, its influence on thermal stability and adhesive properties of the resin were also determined. Figure 2 compares the course of cross-linking process and thermal decomposition of MUPF resin with the addition of
Table 1 Influence of the addition of nano- $\mathrm{SiO}_{2}$ on the reactivity of MUPF resin

\begin{tabular}{llllll}
\hline Amount of nano-SiO & Gel time (s) & \multicolumn{2}{l}{ Activation energy } \\
\cline { 3 - 5 } PBW/100 PBW of MUPF resin & & Kissinger $(\mathrm{kJ} / \mathrm{mol})$ & \multicolumn{2}{l}{ Ozawa $(\mathrm{kJ} / \mathrm{mol})$} \\
\hline MUPF resin + flour filler & 188 & 95.20 & $0.98^{\mathrm{a}}$ & 96.76 & $0.96^{\mathrm{a}}$ \\
1 & 179 & 88.87 & 0.95 & 91.14 & 0.98 \\
1.5 & 203 & 76.30 & 0.97 & 81.23 & 0.99 \\
2 & 198 & 71.51 & 1.0 & 74.18 & 1.0 \\
\hline
\end{tabular}

a Correlation coefficient 
Fig. 1 Changes in viscosity of MUPF in time, depending on the amount of nano- $\mathrm{SiO}_{2}$ (PBW of $\mathrm{SiO}_{2} / 100$ PBW of MUPF) in relation to the reference mixture

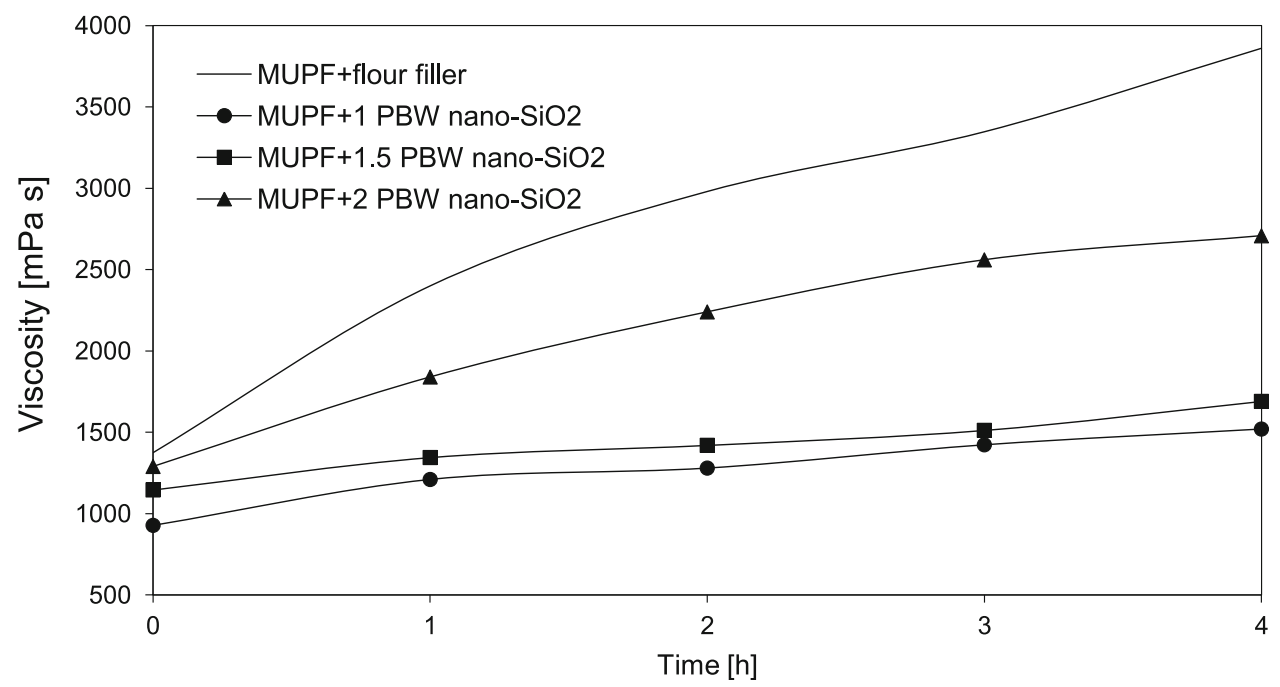

Fig. 2 TG-DSC analysis of MUPF resin containing 2.0 $\mathrm{PBW}$ of $\mathrm{SiO}_{2} / 100 \mathrm{PBW}$ of MUPF in relation to the reference mixture

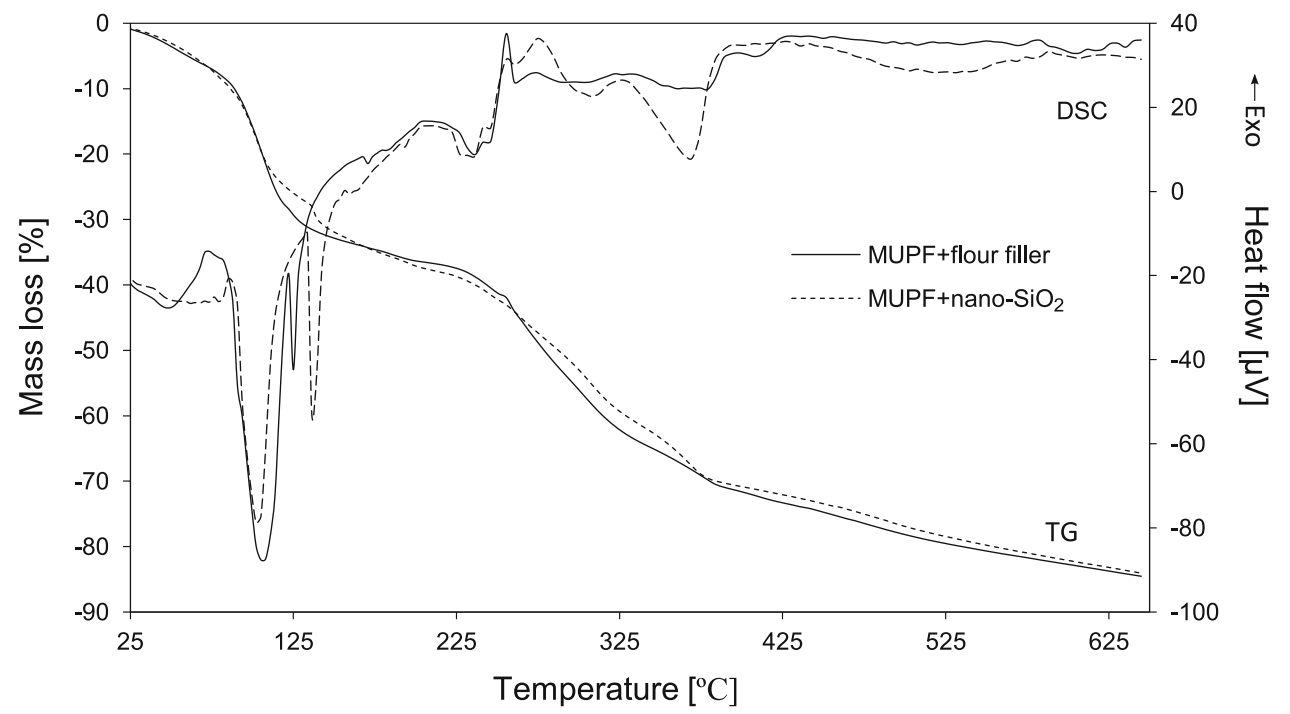

nanofiller in reference to the control adhesive (variant 0 ). It is illustrated by thermogravimetric curves (TG), characterizing changes of the mass, and the curves of differential scanning calorimetry (DSC) determining the thermal effects that accompany the chemical and physical changes in the investigated adhesives. The analysis of the obtained thermograms allows distinguishing the stages of the curing process characteristic of this kind of resin (Jóźwiak et al. 2001; Siimer et al. 2008). The first stage, covering the temperature range from the test beginning up to $70{ }^{\circ} \mathrm{C}$ for the reference adhesive and $80{ }^{\circ} \mathrm{C}$ for the resin with the addition of nano- $\mathrm{SiO}_{2}$, is ascribed to the intensive endothermic drain of water and volatile substances. The literature on the subject (Jóźwiak et al. 2001) shows that the diffuse character of the peak proves that the endothermic processes, directly related to the growth of polycondensate particles, are partially concealed. However, in the analyzed area, small peaks of exothermic character can be spotted which means that the short-term increase in the temperature is caused by the initiation of the adhesive polycondensation process. In case of the mixed resin containing nano- $\mathrm{SiO}_{2}$, this process occurs at a temperature which is higher by $5{ }^{\circ} \mathrm{C}$ than in case of the reference adhesive. The next stage, covering the temperature range from 80 to $140{ }^{\circ} \mathrm{C}$, characterizes the processes of crosslinking with the simultaneous release of water as the reaction product. In this area, two peaks of endothermic character can be spotted. The first one, with the maximum value at $103-107^{\circ} \mathrm{C}$, corresponds to the intensive drain of water and cross-linking of MUPF resin. The other peaks, with the maximum values of thermal effects at $125^{\circ} \mathrm{C}$ for the reference adhesive and $137{ }^{\circ} \mathrm{C}$ for the resin with the addition of nano- $\mathrm{SiO}_{2}$, are characteristic of the final stage of the cross-linking process and splitting off of 
hydroxymethylene groups. This is accompanied by mass decrement of approx. $30 \%$. Based on DSC analysis (Fig. 2), the conclusion was drawn that the curing process of MUPF resin modified with nano- $\mathrm{SiO}_{2}$ requires a smaller amount of thermal energy and the temperature at which the process proceeds is $10{ }^{\circ} \mathrm{C}$ higher than that in the reference sample. This means that the rate of cross-linking reaction of the resin with the addition of nano- $\mathrm{SiO}_{2}$ is higher than that of the resin with the amylaceous filler. It explains the lower values of activation energy attained for the MUPF resin with the addition of nanofiller. The further course of thermograms for both mixed resins, in the temperature range $150-200{ }^{\circ} \mathrm{C}$, is similar and corresponds to the final stage of the curing process, with no clearly marked thermal effects of the exothermic or endothermic kind. According to the data from the literature on this subject, in this range of temperature, methylene bonds disintegrate and gas products are released (Camino et al. 1983; Siimer et al. 2008). At a temperature above $200{ }^{\circ} \mathrm{C}$ the adhesive starts to disintegrate. A small endothermic peak observed at $230{ }^{\circ} \mathrm{C}$ provides evidence that the methylene ether bonds disintegrate. The most intensive disintegration occurs at $250-380{ }^{\circ} \mathrm{C}$. In this range, mass decrement is comparable for both investigated resin mixtures and it reaches the value of $60 \%$. At higher temperatures, the disintegration of the reference resin proceeds in a similar manner. Only in case of the sample of MUPF resin with the addition of nanofiller small endothermic peaks were spotted at 310 and $370{ }^{\circ} \mathrm{C}$ and there was a peak with a maximum value at $525^{\circ} \mathrm{C}$. According to Samaržija-Jovanović et al. (2011), they result from changes in the structure and loss of chemically bonded water that is included in hydroxyl groups in the form of silanol groups. The total mass decrement attained at $600{ }^{\circ} \mathrm{C}$ was similar for both mixed resins and reached $85 \%$. It means that substituting amylaceous filler with fumed silica does not affect the thermal stability of MUPF resin. However, it makes it possible to reduce the amount of energy needed in the cross-linking process of the resin.

From the viewpoint of gluing technology, the adhesive properties can be evaluated by measuring the contact angle $\theta$, the work of adhesion $\mathrm{W}_{\mathrm{a}}$ and free surface energy $\gamma_{\mathrm{SL}}$ on the surface of the investigated materials. Table 2 presents results of measurements of the contact angle for birch wood, MUPF resin and mixed resins produced with the addition of amylaceous filler and nano- $\mathrm{SiO}_{2}$ in the amount stated above. Based on the measured values of contact angle, the values of free surface energy along with its dispersive $\gamma_{\mathrm{s}}^{\mathrm{d}}$ and polar $\gamma_{\mathrm{s}}^{\mathrm{p}}$ components were determined. Table 3 provides data on the values of the theoretical maximum work of adhesion on the phase boundary $\gamma_{\mathrm{S}}$, as well as the ratio of dispersive and polar components of surface energy of the materials in contact. The adhesive
Table 2 Contact angle and free surface energy of wood and the investigated resin mixtures

\begin{tabular}{lllll}
\hline Material/system & $\begin{array}{l}\gamma \\
\left({ }^{\circ}\right)\end{array}$ & $\begin{array}{l}\gamma \\
\left(\mathrm{mJ} / \mathrm{m}^{2}\right)\end{array}$ & $\begin{array}{l}\gamma_{\mathrm{s}}^{\mathrm{d}} \\
\left(\mathrm{mJ} / \mathrm{m}^{2}\right)\end{array}$ & $\begin{array}{l}\gamma_{\mathrm{s}}^{9} \\
\left(\mathrm{~mJ} / \mathrm{m}^{2}\right)\end{array}$ \\
\hline $\begin{array}{l}\text { Birch } \\
\begin{array}{c}\text { MUPF resin }+ \\
\quad \text { flour filler }\end{array}\end{array}$ & $63.08(1.53)$ & 66.58 & 25.31 & 41.27 \\
$\begin{array}{c}\text { MUPF resin }+ \\
\text { nano-SiO }\end{array}$ & $67.30(2.24)$ & 45.06 & 31.65 & 13.41 \\
\hline
\end{tabular}

(...) Standard deviation

properties of the resin with the addition of nanofiller are presented in reference to MUPF resin + flour/wood. The analysis of the obtained results shows that substituting amylaceous filler with nano- $\mathrm{SiO}_{2}$ results in a slight increase of contact angle as well as the value of free surface energy of the system solid-liquid. It is accompanied by a minor decrease in surface tension on the phase boundary and the ratio of its polar components. It leads to the conclusion that the resin mixture including $2 \mathrm{PBW}$ of nano- $\mathrm{SiO}_{2}$ shows slightly worse adhesive properties than the resin with the addition of traditional filler. Investigations conducted by Rudawska (2013) show that the dispersive component of surface energy $\gamma_{\mathrm{s}}^{\mathrm{d}}$ is closely connected with the strength of the adhesive bond: the higher value of $\gamma_{\mathrm{s}}^{\mathrm{d}}$ results in better strength of the bond. Taking the above into account, as well as the fact that values of $\gamma_{\mathrm{s}}^{\mathrm{d}}$ attained in this research work are comparable for each investigated variant, it can be inferred that substituting nanofiller for rye flour does not significantly affect the bond quality of the manufactured plywood.

The influence of the addition of $2 \mathrm{PBW}$ of nano- $\mathrm{SiO}_{2}$ per $100 \mathrm{PBW}$ of MUPF resin on the properties of experimental plywood was investigated as well as the possibility of reducing the amount of adhesive in the process of gluing sheets of veneer by determining the bond quality as well as modulus of rupture and modulus of elasticity in both grain directions in the face layers of plywood. Bond quality was established on the basis of shear tests after water-resistance tests. The obtained results of investigations were compared with properties of plywood produced using amylaceous filler. Results of these tests are presented in Table 4. Symbols " $a, b$, c" included in the table refer to groups of homogeneous means specified on the basis of the post hoc analysis of the Tukey's test.

The post hoc tests prove that the reduction in the amount of resin modified with nano- $\mathrm{SiO}_{2}$ does not significantly affect the bond quality determined after $24 \mathrm{~h}$ of immersion in water. However, the results of shear tests after the boil test with the spread rate of 120 and $100 \mathrm{~g} / \mathrm{m}^{2}$ are slightly decreased. Nevertheless, regardless of the spread rate, the value of shear strength determined after ageing tests exceeds the values required by the standard EN 314-2, i.e. 
Table 3 Parameters determining criteria of adhesion for the investigated resin mixtures and wood

\begin{tabular}{lllllll}
\hline System & $\gamma_{\mathrm{SL}}\left(\mathrm{mJ} / \mathrm{m}^{2}\right)$ & $\mathrm{W}_{\mathrm{a}}\left(\mathrm{mJ} / \mathrm{m}^{2}\right)$ & $\mathrm{W}_{\mathrm{a}}^{\mathrm{d}}\left(\mathrm{mJ} / \mathrm{m}^{2}\right)$ & $\mathrm{W}_{\mathrm{a}}^{\mathrm{p}}\left(\mathrm{mJ} / \mathrm{m}^{2}\right)$ & $\gamma_{\mathrm{L}}^{\mathrm{d}} / \gamma_{\mathrm{S}}^{\mathrm{d}}\left(\mathrm{mJ} / \mathrm{m}^{2}\right)$ & $\gamma_{\mathrm{L}}^{\mathrm{p}} / \gamma_{\mathrm{S}}^{\mathrm{p}}\left(\mathrm{mJ} / \mathrm{m}^{2}\right)$ \\
\hline MUPF resin + flour filler/wood & 7.98 & 56.61 & 47.05 & 103.66 & 1.25 & 0.33 \\
MUPF resin + nano-SiO$/$ wood & 9.55 & 56.66 & 43.55 & 100.10 & 1.25 & 0.28 \\
\hline
\end{tabular}

Table 4 Shear strength of manufactured plywood depending on the amount of adhesive mixture spread onto veneer

\begin{tabular}{|c|c|c|c|}
\hline \multirow[t]{3}{*}{ Kind of mixture } & \multirow{3}{*}{$\begin{array}{l}\text { Adhesive } \\
\text { application } \mathrm{g} / \mathrm{m}^{2}\end{array}$} & \multicolumn{2}{|l|}{$\mathrm{f}_{\mathrm{v}}\left(\mathrm{N} / \mathrm{mm}^{2}\right)$} \\
\hline & & \multicolumn{2}{|l|}{ Type of test } \\
\hline & & $24 \mathrm{~h}$ soaking & Boiling \\
\hline \multirow[t]{4}{*}{ MUPF resin + flour filler } & 180 & $2.21(0.10) \mathrm{a}$ & $1.38(0.18) \mathrm{a}$ \\
\hline & 160 & $2.41(0.35) \mathrm{a}$ & $1.36(0.19) \mathrm{a}$ \\
\hline & 120 & $1.33(0.56) \mathrm{b}$ & $1.02(0.18) b c$ \\
\hline & 100 & $1.07(0.50) \mathrm{b}$ & $0.83(0.27) \mathrm{c}$ \\
\hline \multirow[t]{4}{*}{ MUPF resin + nano- $\mathrm{SiO}_{2}$} & 180 & $2.32(0.18) \mathrm{a}$ & $1.42(0.31) \mathrm{a}$ \\
\hline & 160 & $2.31(0.14) \mathrm{a}$ & $1.48(0.23) \mathrm{a}$ \\
\hline & 120 & $2.14(0.37) \mathrm{a}$ & $1.22(0.28) \mathrm{ab}$ \\
\hline & 100 & $2.04(0.28) \mathrm{a}$ & $1.19(0.25) \mathrm{ab}$ \\
\hline
\end{tabular}

(...) Standard deviation; $\mathrm{a}, \mathrm{b}, \mathrm{c}$-homogenous groups according to Tukey's $t$ test $(\alpha=0.05)$
$1.0 \mathrm{~N} / \mathrm{mm}^{2}$. Therefore, they meet the requirements of class 2 , i.e. plywood for use in humid conditions.

In case of plywood glued with resin modified with amylaceous filler the reduction in spread rate leads to a considerable deterioration of bond quality. It is especially evident in terms of the spread rate of 100 and $120 \mathrm{~g} / \mathrm{m}^{2}$; when the spread rate was $100 \mathrm{~g} / \mathrm{m}^{2}$ the plywood did not meet the requirements of the standard EN 314-2. Moreover, in case of plywood glued with resin modified with amylaceous filler, the values of standard deviation determined for the means of shearing strength after the ageing test are remarkably high, which shows a large dispersion of the obtained measurement results. It arises from the fact that it is difficult to evenly apply the glue to the plywood surface.

The analysis of data included in Table 4 shows that, regardless of the type of applied filler, the bond quality of plywood glued with the resin load of $160 \mathrm{~g} / \mathrm{m}^{2}$ is as good as that of $180 \mathrm{~g} / \mathrm{m}^{2}$. The slight differences that can be noted are statistically insignificant, which is confirmed by the analysis of homogenous groups (for the considered cases, group "a" has been isolated). It is quite significant, as at some point the increased resin load could harm the bond strength as a result of the concentration of internal stresses in the curing process which lead to microcracks even if there is no action of external mechanical forces.

Moreover, it is especially important that the addition of 2 PBW of fumed silica per 100 PBW of the resin made it possible to optimize the utilitarian value of the mixed resin, i.e. the spreading and lubricity were improved and it was easier to evenly apply it to the veneer in the amount of up to $120 \mathrm{~g} / \mathrm{m}^{2}$. Further reduction of the amount of the applied resin made it more difficult to evenly apply it to the veneer surface.

Table 5 presents results of investigations on mechanical properties of the produced experimental plywood, i.e. modulus of rupture and modulus of elasticity parallel and perpendicular to the grain direction in the face layers. The values of these parameters attained for plywood produced using nano- $\mathrm{SiO}_{2}$ are comparable with those obtained for the plywood produced with use of amylaceous filler.

To determine the effect of substituting amylaceous filler with fumed silica on the class of formaldehyde release in the produced plywood, the flask method was used. As expected, substituting nanofiller for amylaceous filler in plywood glued with MUPF resin with the spread rate of $180 \mathrm{~g} / \mathrm{m}^{2}$ makes it possible to reduce the formaldehyde emission by $25 \%$ (Fig. 3). The obtained results correspond with those attained by other authors. Introducing small amounts of nano- $\mathrm{SiO}_{2}$ into the UF resin reduced the formaldehyde release from particleboards, OSB, plywood and medium density fiberboards (MDF) glued with UF resin (Higuchi and Sakata 1981; Lin et al. 2006; Roumeli et al. 2012; Salari et al. 2013). The literature review shows that the reduction of formaldehyde release from boards glued with UF resin modified by a small amount of nano- $\mathrm{SiO}_{2}$ can be ascribed to absorption properties of the well-developed surface of silica (Leonovich et al. 2002; Arafa et al. 2004; Gun'ko et al. 2005). Researchers also found out that the physical adsorption of formaldehyde is accompanied by the formation of hydrogen bonds between silanol groups on the silica surface and the active groups of the resin and formaldehyde (Roumeli et al. 2012; Salari 2013). Obviously, the decrease in formaldehyde 
Table 5 Bending strength and modulus of elasticity of manufactured plywood depending on the amount of adhesive mixture spread onto veneer

\begin{tabular}{|c|c|c|c|c|c|}
\hline Kind of mixture & $\begin{array}{l}\text { Adhesive } \\
\text { application } \mathrm{g} / \mathrm{m}^{2}\end{array}$ & $\mathrm{f}_{\mathrm{m}}(\mathrm{II})\left(\mathrm{N} / \mathrm{mm}^{2}\right)$ & $\mathrm{E}_{\mathrm{m}}(\mathrm{II})\left(\mathrm{N} / \mathrm{mm}^{2}\right)$ & $\mathrm{f}_{\mathrm{m}}(\perp)\left(\mathrm{N} / \mathrm{mm}^{2}\right)$ & $\mathrm{E}_{\mathrm{m}}(\perp)\left(\mathrm{N} / \mathrm{mm}^{2}\right)$ \\
\hline \multirow[t]{4}{*}{ MUPF resin + flour filler } & 180 & $142(2.9) \mathrm{ab}$ & 14760 (300)a & $39(2.0) \mathrm{c}$ & 1790 (40)abc \\
\hline & 160 & $137(8.0) \mathrm{b}$ & $14600(250) \mathrm{a}$ & $38(2.7) \mathrm{abc}$ & $1690(100) \mathrm{a}$ \\
\hline & 120 & 143 (14.1)ab & $13700(850) \mathrm{a}$ & $35(3.5) \mathrm{ab}$ & 1800 (90)abc \\
\hline & 100 & 147 (13.8)ab & $14700(620) \mathrm{a}$ & $36(4.2) \mathrm{abc}$ & $1780(120) a b c$ \\
\hline \multirow[t]{4}{*}{ MUPF resin + nano- $\mathrm{SiO}_{2}$} & 180 & $152(15.2) \mathrm{ab}$ & $14760(900) \mathrm{a}$ & $36(2.6) \mathrm{abc}$ & $1950(70) \mathrm{d}$ \\
\hline & 160 & $156(3.2) \mathrm{a}$ & $14540(400) \mathrm{a}$ & $35(2.0) \mathrm{a}$ & $1890(100) \mathrm{cd}$ \\
\hline & 120 & $146(8.2) \mathrm{ab}$ & $14160(600) \mathrm{a}$ & $38(2.5) b c$ & $1760(80) \mathrm{ab}$ \\
\hline & 100 & $154(10.5) \mathrm{a}$ & $14350(300) \mathrm{a}$ & $37(3.4) \mathrm{abc}$ & $1810(50) b c$ \\
\hline
\end{tabular}

(...) Standard deviation; $\mathrm{a}, \mathrm{b}, \mathrm{c}$ - homogenous groups according to Tukey's $t$ test $(\alpha=0.05)$

Fig. 3 Formaldehyde release from experimental plywood, depending on the amount of the adhesive mixture applied to veneer sheets and the kind of filler

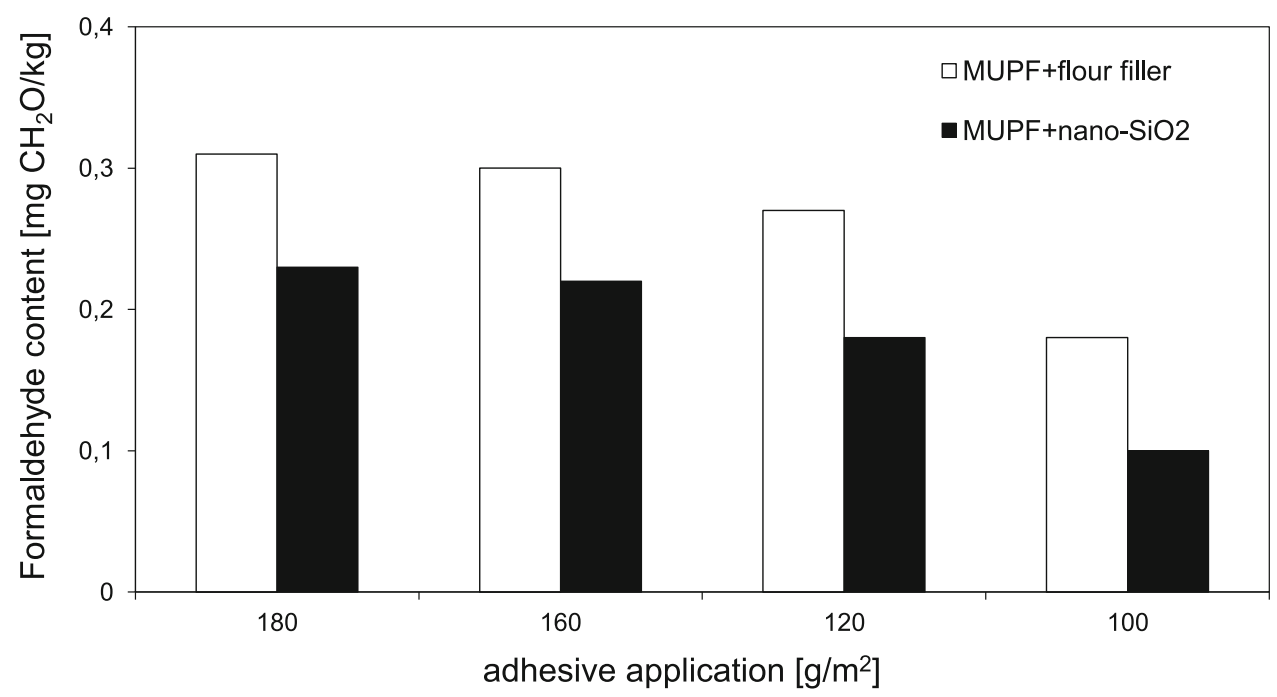

emission results from the limited amount of MUPF resin used to produce the investigated plywood. Restraining the application of MUPF resin by the addition of nano- $\mathrm{SiO}_{2}$ down to $120 \mathrm{~g} / \mathrm{m}^{2}$ made it possible to reduce the free formaldehyde by another $20 \%$.

\section{Conclusion}

The conducted investigations led to the conclusion that introducing fumed silica into MUPF resin in the amount of 2 PWW per 100 PBW of the resin makes it possible to expand its durability, increase its reactivity (which is expressed by the decrease of activation energy) and optimize the process of gluing sheets of veneer. It was also shown that substituting the amylaceous filler with nanoparticles of fumed silica makes it possible to reduce the spread rate of the applied mixed resin by approximately $30 \%$ (from 180 down to $120 \mathrm{~g} / \mathrm{m}^{2}$ ) and, at the same time, maintain high water resistance of the produced plywood. In industrial conditions, such considerable reduction in the amount of the adhesive used would contribute to cutting down the costs of manufacturing water resistant plywood glued with MUPF resin.

The use of nanosilica as a filler for MUPF resin results in significant decrease of formaldehyde release from the produced plywood regardless of the spread rate of the mixed resin in the process of gluing plywood.

Acknowledgments We would like to express our gratitude to Dagmara Panowicz MSc for her help and support in implementing this research project.

Open Access This article is distributed under the terms of the Creative Commons Attribution 4.0 International License (http:// creativecommons.org/licenses/by/4.0/), which permits unrestricted use, distribution, and reproduction in any medium, provided you give appropriate credit to the original author(s) and the source, provide a link to the Creative Commons license, and indicate if changes were made.

\section{References}

Arafa IM, Fares MM, Barham AS (2004) Sol-gel preparation and properties of interpenetrating, encapsulating and blend silica- 
based urea-formaldehyde hybrid composite materials. Eur Polym J 40(7):1477-1487

Azinfar B, Ramazani SAA (2013) In situ preparation and property investigation of polypropylene/fumed silica nanocomposites. Polym Compos 35(1):37-44

Barthel H, Dreyer M, Gottschalk-Gaudig T, Litvinov V, Nikitina E (2002) Fumed silica—rheological additive for adhesives, resins and paints. Macromol Symp 187:573-584

Bonnefond A, Reyes Y, Peruzzo P, Ronne E, Fare J, Paulis M, Leiza JR (2013) Effect of the incorporation of modified silicas on the final properties of wood adhesives. Macromol React Eng 7(10):527-537

Camino G, Operti L, Trossarelli L (1983) Mechanism thermal degradation of urea-formaldehyde polycondensates. Polym Degrad Stabil 5:161-172

Carneiro C, Vieira R, Mendes AM, Magalhães FD (2012) Nanocomposite acrylic paint with self-cleaning action. J Coat Technol Res 9(6):687-693

Dukarska D (2013) The effect of an addition of nano- $\mathrm{SiO}_{2}$ to urea resin on the properties of boards manufactured from rape straw. Ann WULS-SGGW For Wood Technol 82:242-245

Dukarska D, Łęcka J (2009) The effect of an addition of $\mathrm{TiO}_{2}$ and $\mathrm{SiO}_{2}$ nanomolecules to phenolic resin on properties and colour of glue lines in exterior plywood. Ann WULS-SGGW For Wood Technol 68:198-202

EN 310 (1993) Wood-based panels. Determination of modulus of elasticity in bending and of bending strength. European Committee for Standardization, Brussels

EN 314-1 (2004) Plywood. Bonding quality. Part 1: test method. European Committee for Standardization, Brussels

EN 314-2 (1993) Plywood. Bond quality. Requirements. European Committee for Standardization, Brussels

EN 717-3 (1996) Wood-based panels. Determination of formaldehyde release. Part 3. Formaldehyde release by the flask method. European Committee for Standardization, Brussels

Gun'ko VM, Mironyuk IF, Zarko VI (2005) Morphology and surface properties of fumed silicas. J Colloid Interface Sci 289(2):427-445

Higuchi M, Sakata I (1981) Klebstoff aus einem harnstoff- formaldehyd-harz. German Patent DE 3026015

Huang Y, Jiang S, Wu L, Hua Y (2004) Characterization of LLDPE/nano- $\mathrm{SiO}_{2}$ composites by solid-state dynamic mechanical spectroscopy. Polym Test 23:9-15

Jesionowski T, Żurawska J, Krysztafkiewicz A (2002) Surface properties and dispersion behaviour of percipitated silicas. J Mater Sci 37:1621-1633

Jóźwiak M, Proszyk S, Jabłoński W (2001) Badania nad procesami żelowania i utwardzania żywic melaminowo-mocznikowoformaldehydowych przeznaczonych do produkcji tworzyw drzewnych (Studies on the gelation and curing processes of melamineurea-formaldehyde adhesive resins applied to production of wood based materials). Folia Forest Pol Ser B 32:31-40 (in Polish)

Kandelbauer A, Wuzella G, Mahendran A, Taudes I, Widsten P (2009) Model-free kinetic analysis of melamine-formaldehyde resin cure. Chem Eng J 152(2-3):556-565

Kim S, Kim HJ, Kim HS, Lee YK, Yang HS (2006) Thermal analysis study of viscoelastic properties and activation energy of melamine-modified urea-formaldehyde resins. J Adhesion Sci Technol 20(8):803-816

Kissinger HE (1957) Reaction kinetics in differential thermal analysis. Anal Chem 29(11):1702-1706

Kúdela J, Liptáková E (2006) Adhesion of coating materials to wood. J Adhesion Sci Technol 20(8):875-895

Leder G, Ladwig T, Valter V, Frahn S, Meyer J (2002) New effects of fumed silica in modern coatings. Prog Org Coat 45:139-144
Leonovich AA, Kovrizhnykh LP, Korneev VI, Bodoyavlenskaya GA, Medvedeva IN (2002) Silicon dioxide sol as a component of urea-formaldehyde adhesive. Rus J Appl Chem 75(8):1336-1338

Lin Q, Yang G, Liu J, Rao J (2006) Property of nano- $\mathrm{SiO}_{2} /$ urea formaldehyde resin. Front For China 2:230-237

Liptáková E, Kúdela J (1994) Analysis of wood-wetting process. Holzforschung 48:139-144

Liptáková E, Kúdela J (2002) Study of the system wood-coating material. Part 2. Wood-solid coating material. Holzforschung 56:547-557

Moon SH, You JS, Kim JS, Kweon JO, Ahn JB, Noh ST (2013) Reological behavior and film characterization of fumed silica dispersion in carboiimide based UV-curable coating material. Macromol Res 21:146-152

Ozawa T (1965) A new method of analyzing thermogravimetric data. Bull Chem Soc Jpn 38(1):1881-1886

Periadurai T, Vijayakumar CT, Balasubramanian M (2010) Thermal decomposition and flame retardant behaviour of $\mathrm{SiO}_{2}$-phenolic nanocomposite. J Anal Appl Pyrol 89:244-249

PN-C-89352-3 (1996) Kleje do drewna. Metody badań. Oznaczanie czasu żelowania. (Wood adhesives. Test methods. Determination of gelation time). Polish Committee for Standardization (in Polish)

Proszyk S (1990) Investigation on the durability of filled ureaformaldehyde adhesives against selected mould fungi. Mater Organ 25(2):123-133

Roumeli E, Papadopoulou E, Pavlidou E, Vourlias G, Bikiaris D, Paraskevopoulos KM, Chrissafis K (2012) Synthesis, characterization and thermal analysis of urea-formaldehyde/nanoSiO resin. Thermochim Acta 527:33-39

Royall CP, Donald AM (2002) Surface properties and structural collapse of silica in matte water-based lacquers. Langmuir 18(24):9519-9526

Rudawska A (2013) Wybrane zagadnienia konstytuowania połączeń adhezyjnych jednorodnych i hybrydowych (Selected issues in constituing homogeneous and hybrid adhesive joint). Publishing House of Lublin University of Technology, Lublin, Polad (in Polish)

Sadej-Bajerlain M, Gojzewski H, Andrzejewska E (2011) Monomer/modified nanosilica systems: Photopolymeryzation kinetics and composite characterization. Polymer 52:1495-1503

Sadhan CJ, Sachin J (2001) Dispersion of nanofillers in high performance polymers using reactivity solvents as processing aids. Polymer 42:6897-6905

Salari A, Tabarsa T, Khazaeian A, Seraeian A (2013) Improving some of applied properties of oriented strand board (OSB) made from underutilized low quality paulownia (Paulownia fortunie) wood employing nano- $\mathrm{SiO}_{2}$. Ind Crop Prod 42:1-9

Samaržija-Jovanović S, Jovanović V, Konstantinović S, Marković G, Marinović-Cincovic M (2011) Thermal behavior of modified urea-formaldehyde resins. J Therm Anal Calorim 104: $1159-1166$

Sellers T (1989) Diisocyanate/furfural adhesives for bonding plywood. For Prod J 39:53-56

Shi J, Li J, Zhou W, Zhang D (2007) Improvement of wood properties by urea-formaldehyde resin and nano-SiO 2 . Front For China 2(1):104-109

Shirono H, Amano Y, Kawaguchi M, Kato T (2001) Characteristics of alkylotrimethoxysilane-treated fumed silicas and rheological behavior of fumed silica suspension in a epoxy resin. J Colloid Interface Sci 239:555-562

Siimer K, Christjanson P, Kaljuvee T, Pehk T, Lasn I, Saks I (2008) TG-DTA study of melamine-urea-formaldehyde resins. J Therm Anal Calorim 92:19-27

Sow C, Riedl B, Blanchet P (2011) UV-waterborne polyurethaneacrylate nanocomposite coatings containing alumina and silica nanoparticles for wood: mechanical, optical and 
thermal properties assessment. J Coat Technol Res $8(2): 211-221$

Vega-Baudrit J, Navarro-Bañón V, Vázquez P, Martín-Matrínez JM

(2006) Addition of nanosilica with different silanol content to thermoplastic polyurethane adhesives. Int $\mathbf{J}$ Adhes Adhes 26:378-387
Wang ZJ, Gu ZB, Hong Y, Cheng L, Li ZF (2011) Bonding strength and water resistance of starch-based wood adhesive improved by silica nanoparticles. Carbohydr Polym 86(1):72-76 